\title{
Low Voltage in Limb Leads Only by ECG
} Finding

National Cancer Institute

\section{Source}

National Cancer Institute. Low Voltage in Limb Leads Only by ECG Finding. NCI

Thesaurus. Code C116133.

An electrocardiographic finding of small QRS amplitudes (less than 500 microvolts) in all limb leads. (CDISC) 